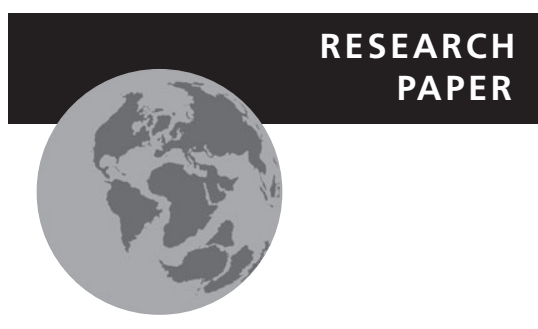

\section{The role of climate and plant functional trade-offs in shaping global biome and biodiversity patterns}

\author{
Björn Reu ${ }^{1,2 \star}$, Raphaël Proulx ${ }^{1,3}$, Kristin Bohn ${ }^{1}$, James G. Dyke ${ }^{1}$, \\ Axel Kleidon ${ }^{1}$, Ryan Pavlick ${ }^{1}$ and Sebastian Schmidtlein ${ }^{2}$
}

\begin{abstract}
${ }^{1}$ Max-Planck-Institute for Biogeochemistry, PO Box 1001 64, 07701 Jena, Germany, ${ }^{2}$ Institute of Geography, University Bonn, Meckenheimer Allee 166, 53115 Bonn, Germany,

${ }^{3}$ Département de Chimie-Biologie, Université du Québec à Trois-Rivières, 3351 des Forges,

Trois-Rivières, G9A 5H7, Canada
\end{abstract}

\begin{abstract}
Aim Two of the oldest observations in plant geography are the increase in plant diversity from the poles towards the tropics and the global geographic distribution of vegetation physiognomy (biomes). The objective of this paper is to use a processbased vegetation model to evaluate the relationship between modelled and observed global patterns of plant diversity and the geographic distribution of biomes.
\end{abstract}

Location The global terrestrial biosphere.

Methods We implemented and tested a novel vegetation model aimed at identifying strategies that enable plants to grow and reproduce within particular climatic conditions across the globe. Our model simulates plant survival according to the fundamental ecophysiological processes of water uptake, photosynthesis, reproduction and phenology. We evaluated the survival of an ensemble of 10,000 plant growth strategies across the range of global climatic conditions. For the simulated regional plant assemblages we quantified functional richness, functional diversity and functional identity.

Results A strong relationship was found (correlation coefficient of 0.75 ) between the modelled and the observed plant diversity. Our approach demonstrates that plant functional dissimilarity increases and then saturates with increasing plant diversity. Six of the major Earth biomes were reproduced by clustering grid cells according to their functional identity (mean functional traits of a regional plant assemblage). These biome clusters were in fair agreement with two other global vegetation schemes: a satellite image classification and a biogeography model (kappa statistics around 0.4).

Main conclusions Our model reproduces the observed global patterns of plant diversity and vegetation physiognomy from the number and identity of simulated plant growth strategies. These plant growth strategies emerge from the first principles of climatic constraints and plant functional trade-offs. Our study makes important contributions to furthering the understanding of how climate affects patterns of plant diversity and vegetation physiognomy from a process-based rather than a phenomenological perspective.

\section{Keywords}

Biogeography, climate-biodiversity relationship, functional diversity, functional identity, functional richness, PFT, plant functional traits, tolerance hypothesis, vegetation model. 


\section{INTRODUCTION}

Two of the oldest observations in plant geography are: (1) plant diversity increases from the poles towards the tropics, and (2) the global geographic distribution of vegetation physiognomy (biomes) is independent of phylogenetic taxonomy (von Humboldt, 1808; Schimper, 1898). While previous explanations for these patterns have mostly been of a phenomenological nature, we show in this paper how they can be understood from first principles in terms of climatic constraints and plant functional trade-offs.

Plant community assembly is the result of functional tradeoffs that individual plants face when dealing with the constraints imposed by their biotic and abiotic environment (Tilman, 1988, 1990). Plant functional traits are defined as the morphological, phenological or physiological characteristics of an organism affecting its ability to acquire (allocate) resources to growth, maintenance and reproduction (Violle et al., 2007). Because the climate imposes fundamental limits to resource availability, such as sunlight, water and nutrients, plants have evolved different combinations of functional traits allowing them to tolerate a range of climatic constraints (Schwinning \& Ehleringer, 2001; Reineking et al., 2006). For example, similar climates around the globe have led to the convergence of plant traits yielding similar functions (Ackerly et al., 2000; Reich et al., 2003), such as the repeated and independent evolution of $\mathrm{C}_{4}$ and crassulacean acid metabolism (CAM) photosynthesis in water-limited environments (Ehleringer \& Monson, 1993). Adaptations to climatic constraints come with an associated cost, which is reflected by functional trade-offs between growth, maintenance and reproductive functions at the level of an individual plant.

As an example, plants must trade off between allocating assimilates to root versus shoot growth in order to deal with the spatial separation of water and light (Thornley, 1972). This rootto-shoot allocation trade-off has manifested into diverse plant morphologies across species growing along environmental gradients. In water-limited climates (e.g. hot and cold deserts), plants benefit from allocation to root growth, while they benefit from allocation to shoot growth in light-limited environments (Mokany et al., 2006). While allocation of assimilates to root versus shoot growth is beneficial under one suite of environmental constraints, it also has an associated energetic cost under other constraints, and a functional trade-off emerges between these traits.

The increasing richness of plants morphology and taxonomy from the poles to the tropics has been reported for many plant species and taxa (cf. Hillebrand, 2004) and is well known as the latitudinal biodiversity gradient. Several hypotheses have been proposed to explain the global geographic patterns of biodiversity (reviewed in Mittelbach et al., 2001, and Hawkins et al., 2003). A majority of these hypotheses are derived from statistical models directly linking the observed plant species richness to current climate variables (Francis \& Currie, 2003; Kreft \& Jetz, 2007). The tolerance hypothesis states that plant species assemblages are composed of growth strategies that can survive the constraints imposed by the climate (reviewed in Currie et al., 2004). Less constraining climates would allow species assemblages to host a larger number of different trait combinations, whereas this potential functional trait space would be reduced under more constraining climates. However, the tolerance hypothesis has never been verified empirically. In this paper we show that the functional richness modelled with a global vegetation model is a surrogate for the observed latitudinal gradient in plant species richness.

To classify the global vegetation physiognomy, semiempirical schemes have been developed that delineate biomes from temperature, precipitation and water balance conditions (Schimper, 1898; Köppen, 1936; Holdridge, 1947; Whittaker, 1975). Dynamic global vegetation models (DGVMs) (Prentice et al., 1992; Neilson, 1995) use climate variables to constrain the geographic distribution of plant functional types (PFTs) (Box, 1981, 1996; Woodward, 1987). In these approaches, biomes are only implicitly delineated from climatic constraints acting upon PFTs (Woodward, 1987; Woodward \& Kelly, 1997). Since PFTs are parameterized from expert knowledge, DGVMs have never been explicitly linked to plant functional trade-offs. In this paper we show that biomes can be reconstructed by clustering regional plant assemblages sharing a similar functional identity.

The objective of this paper is to explore a novel approach for evaluating the relationship between modelled and observed global patterns of (1) plant species richness and (2) the geographic distribution of biomes. For this purpose, we used a process-based vegetation model identifying plant growth strategies (PGS) that can tolerate the climate in grid cells of coarse spatial resolution. The model has previously been successful in qualitatively mapping the global patterns of plant species richness (Kleidon \& Mooney, 2000) and representing geographic variations in species evenness and rank-abundance distributions (Kleidon et al., 2009).

\section{METHODS}

To simulate the geographic variation of vegetation, we used the process-based plant diversity model developed by Kleidon \& Mooney (2000), hereafter called JeDi (the Jena diversity model). Ecological terminology is sophisticated because it seeks to differentiate biological phenomena occurring in the real world, while models of such phenomena will typically simplify and aggregate this knowledge. Table 1 provides a glossary of the central terms used in this paper, as they are commonly defined in the context of the research fields of plant community ecology and vegetation modelling. In the following sections, we provide a brief description of the model and how it implements plant functional trade-offs. We proceed to quantify the functional richness (FR), functional diversity (FD) and functional identity (FI) of simulated plant assemblages. Finally, we compare the measures of FR and FI with observed patterns and investigate the relationship between FR and FD. 


\section{Model description}

\section{Model initialization}

We define a PGS as the combination of 12 plant functional traits (Table 2) controlling plant growth, life history and ecophysiological trade-offs. Each functional trait is a model parameter associated with a cost-benefit function that will, along with other functional traits, determines the survival of a PGS subjected to different climatic constraints. To initialize the model we use a Monte Carlo procedure generating 10,000 PGS that evenly fill the potential trait space (Fig. 1). This modelling approach has one main assumption: the minimum functional dissimilarity among
PGS is entirely fixed by the Monte Carlo procedure. Geographic variation in plant functional redundancy (functional niche packing) is therefore not allowed in this model.

\section{Model simulation}

The model simulates plant growth from fundamental ecophysiological processes: photosynthesis, respiration, resource allocation, phenology and reproduction. Each PGS grows at a daily time-step under a particular climate within a global grid with a spatial resolution of $1^{\circ}$. For regional climate input we use daily values of solar and terrestrial radiation, as well as surface tem-

Table 1 Glossary of the central terms used in this paper as they are commonly defined in the context of plant community ecology and their relation to the basic functioning of the Jena diversity (JeDi) model.

\begin{tabular}{|c|c|c|}
\hline Terminology & Plant community ecology & JeDi model \\
\hline Plant functional trait & $\begin{array}{l}\text { A morphological, phenological or physiological } \\
\text { characteristic of an organism affecting its ability to } \\
\text { acquire and allocate resources (Violle et al., 2007) }\end{array}$ & $\begin{array}{l}\text { A parameter controlling a cost-benefit function that } \\
\text { affects a plant's ability to acquire and allocate } \\
\text { resources (Table } 2 \text { ) }\end{array}$ \\
\hline Plant growth strategy (PGS) & $\begin{array}{l}\text { Life form (Raunkiaer, 1934), plant ecological strategy } \\
\text { (Grime, 1974; Westoby et al., 2002) or plant } \\
\text { functional type (Box, 1981; Diaz \& Cabido, 2001) }\end{array}$ & Combination of 12 parameters (Table 2) \\
\hline Functional richness (FR) & Number of observed PGS & Number of surviving PGS \\
\hline Regional plant assemblage & Species pool at spatial scales of varying resolution & Surviving PGS in a spatial grid cell of $1^{\circ}$ resolution \\
\hline Functional diversity (FD) & $\begin{array}{l}\text { Species dissimilarity in the functional trait space } \\
\text { (Petchey \& Gaston, 2002) }\end{array}$ & $\begin{array}{l}\text { PGS dissimilarity in the 12-dimensional parameter } \\
\text { space (Fig. 1) }\end{array}$ \\
\hline Functional identity (FI) & $\begin{array}{l}\text { The mean (weighted) trait values of species in a plant } \\
\text { community (Garnier et al., 2004) }\end{array}$ & $\begin{array}{l}\text { The mean (unweighted) parameter values of PGS in a } \\
\text { regional plant assemblage (Fig. 1) }\end{array}$ \\
\hline Functional trade-off & $\begin{array}{l}\text { Negative correlation between two functional traits } \\
\text { among species in a plant community (Westoby et al., } \\
\text { 2002, Reich et al., 2003) }\end{array}$ & $\begin{array}{l}\text { Negative correlation between two parameters among } \\
\text { PGS in a regional plant assemblage (Fig. 1) }\end{array}$ \\
\hline
\end{tabular}

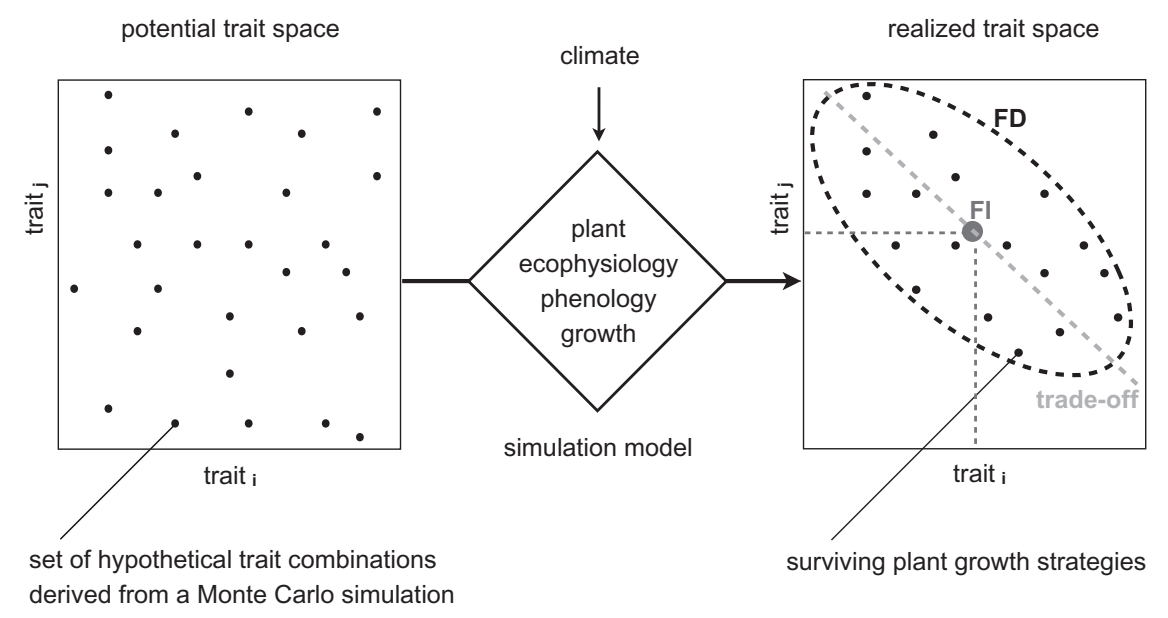

Figure 1 Illustration of the global vegetation modelling approach implemented in this study (after Kleidon \& Mooney, 2000). From a randomly sampled potential trait space, the model selects plant growth strategies (PGS; a combination of 12 parameters) that are able to survive the regional climatic constraints of a grid cell of $1^{\circ}$ spatial resolution. The realized trait space of a grid cell is defined as a regional plant assemblage, in which the number of surviving PGS defines its functional richness (FR). The functional diversity (FD) is a measure of the functional dissimilarity among the PGS, while the functional identity (FI) is the centroid of the realized trait space within the global trait space. A plant functional trade-off is defined as the negative correlation between two functional traits (grey line). 
Table 2 Description of the 12 plant functional traits used in the Jena diversity model (JeDi).

\begin{tabular}{|c|c|c|c|}
\hline Model trait & Effect on plant growth & Cost & Benefit \\
\hline $\mathrm{t} 01$ & Growth response time to soil moisture conditions & Less time for $\mathrm{C}$ assimilation & Tolerance to water shortage \\
\hline $\mathrm{t} 02$ & Growth response time to temperature conditions & Less time for $\mathrm{C}$ assimilation & Tolerance to frost damage \\
\hline $\mathrm{t} 03$ & Allocation to reproduction & Less growth & Increased reproduction \\
\hline $\mathrm{t} 04$ & Allocation of assimilates to above-ground growth & C expenditure for maintenance & Increased growth \\
\hline t05 & Allocation of assimilates to below-ground growth & C expenditure for maintenance & Increased growth \\
\hline t06 & Allocation of assimilates to storage & Less growth & Tolerance to C shortage \\
\hline t07 & Relative allocation to above-ground structure versus leaves & Less photosynthetic capacity & Increased access to light \\
\hline t08 & Relative allocation to below-ground structure versus fine roots & Less water uptake & Increased access to water \\
\hline t09 & Senescence response time to net productivity conditions & Less time for $\mathrm{C}$ assimilation & Tolerance to climatic variability \\
\hline $\mathrm{t} 10$ & Relative senescence of leaves versus roots & Less growth & Tolerance to climatic variability \\
\hline $\mathrm{t} 11$ & Initial amount of assimilates ('seed size') & $\mathrm{C}$ expenditure for maintenance & Increased seedling survival \\
\hline $\mathrm{t} 12$ & Regulation of light-use efficiency & Increased respiration & Increased photosynthetic capacity \\
\hline
\end{tabular}

All traits are associated to ecophysiological costs and benefits in terms of plant growth and survival.

perature and precipitation (Sheffield et al., 2006). From these climate variables the model calculates land surface processes, such as infiltration, evaporation, root-water uptake and surface runoff, that act as additional constraints on plant growth. To complete a model run, 30 years of reanalysis climate data from 1960-90 (Sheffield et al., 2006) were repeated until a simulation period of 210 years was completed.

\section{Success criterion}

A PGS starts its life cycle with a fixed amount of seed carbon (t11, Table 2). A PGS is judged to have survived if it is able to reproduce at least one seed during its lifetime. This requires the allocation of the initial amount of seed carbon to its reproduction pool. All PGS that survive within a grid cell enter the realized trait space (Fig. 1), hereafter called a regional plant assemblage (Table 1). At the global scale, the trait space depicts all PGS that can theoretically tolerate one of the Earth's climatic constraints.

\section{Analysis of model results}

We extract FR, FD and FI measures (Table 1) for each regional plant assemblage based on the functional traits of surviving PGS. Regions where none of the simulated PGS are predicted to survive, such as Antarctica, Greenland, Sahara and the Tibetan Plateau, are not considered in further analyses.

\section{Relationship between functional and species richness}

We derived FR from the number of surviving PGS per regional plant assemblage (grid cell) (Fig. 2). Since this number depends on the initial number of PGS, values per grid cell are normalized to the maximum number of surviving PGS in any of the grid cells (i.e. the grid cell with the greatest number of PGS has a value of 1). This measure of FR is robust to variation in the initial conditions, even when decreasing the number of initial PGS from 10,000 to 1000 (not shown).

A very limited number of datasets have compiled the global geographic variation in plant species richness from observed data. To evaluate the relationship between the modelled FR and the observed species richness, we used the published data of Kier et al. (2005), where plant species richness is estimated at the level of ecoregions (Olson et al., 2001). We spatially aggregated our modelled estimates of FR to the level of ecoregions (http://www.worldwildlife.org/science/data/item 1875.html) and used the FR of ecoregions as a correlate of the observed species richness. Finally, we calculated the standard variation of the modelled FR across the grid cells of an ecoregion in order to compare it with the uncertainty range reported by the authors for the observed plant species richness. We retained only the observed species richness estimates that were classified as being of good or moderate quality by Kier et al. (2005).

\section{Plant functional diversity in the trait space}

Regional plant assemblages differ in the number of PGS they host. The cost-benefit functions associated with each plant functional trait in JeDi impose a heterogeneous structure to the distribution of surviving PGS in the 12-dimensional trait space. The proposition behind the climate tolerance hypothesis is that increasing the FR of regional plant assemblages is reflected by an expansion in the trait space of surviving PGS, which is due to a reduction of the functional constraints on plant growth and survival. To verify this proposition, we calculated the FD of each regional plant assemblage (Fig. 1). To rescale all traits to a comparable unit range, we divided each trait by its global maximum (i.e. the maximum value obtained across all grid cells). Then, if we let $S$ be the number of PGS in the regional assemblage, and $d_{i j}$ is the Euclidean distance between PGS $i=1, \ldots, S$ and PGS $j=1, \ldots, S$ in the 12-dimensional trait space, FD is defined as: 


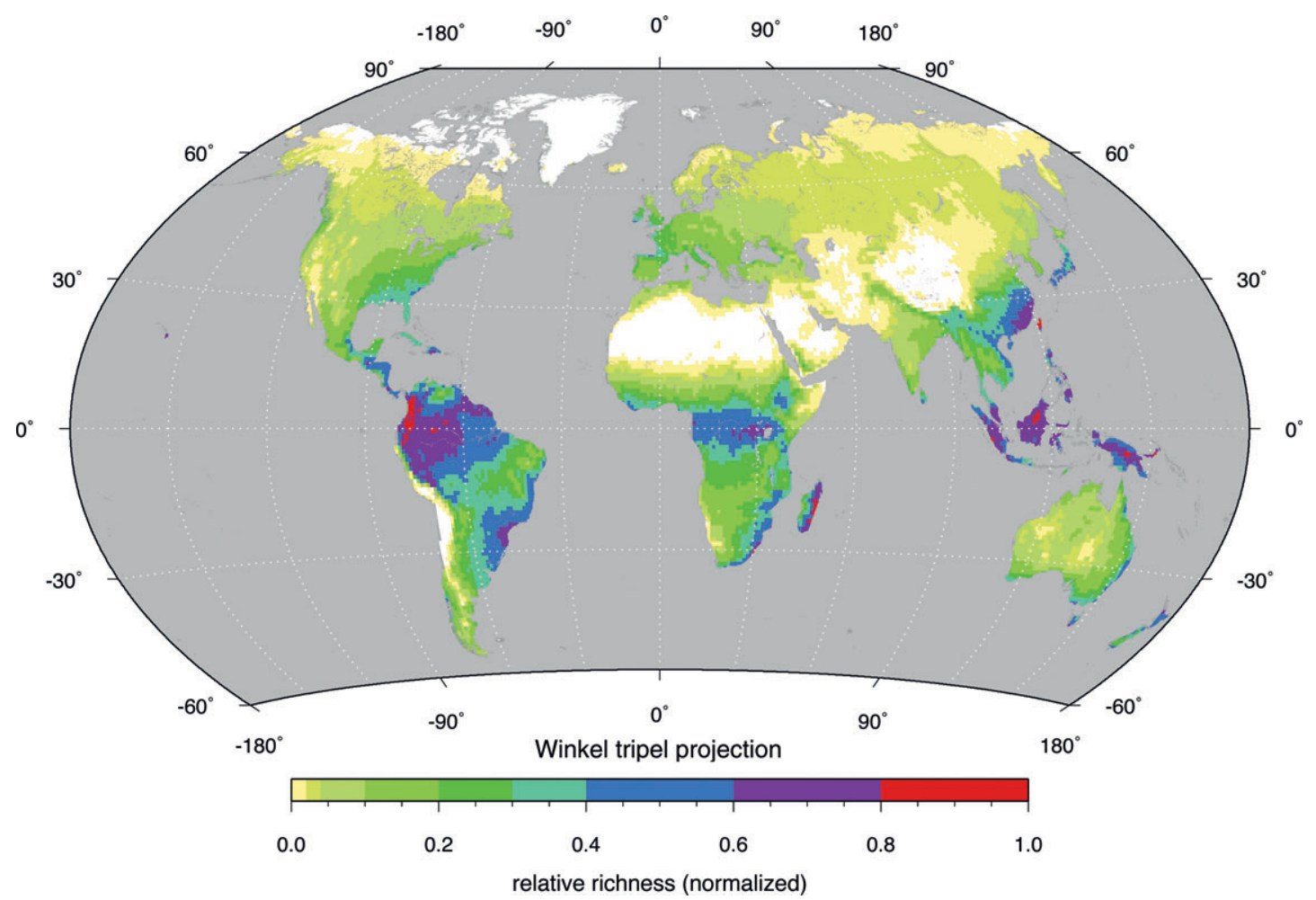

Figure 2 Modelled functional richness (FR; Table 1) at each grid cell. Values are expressed in relative numbers (i.e. normalized to the maximum FR).

$\mathrm{FD}=\frac{1}{S^{2}} \sum_{i=1}^{S-1} \sum_{j=i+1}^{S} d_{i j}^{2}$.

FD is obtained by adding up the squares of all $d_{i j}$ in the subdiagonal triangular half of the distance matrix and dividing by the square of $S . F D$ is a multivariate measure of heterogeneity similar to the variance (Anderson, 2001).

\section{Plant functional identity in the trait space}

The second proposition we examine is that different PGS can tolerate different climatic constraints. Consequently, surviving PGS in the model should determine the FI of a regional plant assemblage. To verify this proposition we calculated the FI of each regional plant assemblage as follows: $\mathrm{FI}=\left[f_{1}, \ldots, f_{k}\right]$, where $f$ is the mean of a functional trait calculated using all PGS in one plant assemblage and $k$ is the number of traits $(k=12$; Table 2$)$. The vector $\left[f_{1}, \ldots, f_{k}\right]$ determines the centroid of a regional plant assemblage in the global trait space realized by the model (Fig. 1).

To further investigate whether spatially contiguous plant assemblages share a similar identity, we clustered grid cells according to their FI. For this purpose, we used the $k$-means algorithm implemented in the R package 'stats'. To assess the quality of the cluster separation we used the simple structure index implemented in the R package 'vegan'. We compared our clustering results based on FI with two other vegetation classification schemes. The first scheme is a biome map derived from satellite imagery representing natural vegetation categories (Ramankutty \& Foley, 1999). The second scheme derives biomes from empirical relationships implemented in a biogeographic model (BIOME1; Prentice et al., 1992). We ran BIOME1 with the same climate input as that used for the JeDi model. Finally, we assessed the level of agreement among the two biome classifications and the FI clusters using the kappa statistic (Monserud \& Leemans, 1992).

To assist our interpretation, we identified plant functional trade-offs responsible for the physiognomy of regional plant assemblages. This was done by calculating all possible pairwise correlation coefficients (Pearson's $r$ ) between two plant functional traits among all PGS for each grid cell (Fig. 1). We then reported for each FI biome cluster the mean $( \pm 1 \mathrm{SD})$ of the three strongest correlations. This was done by averaging pairwise correlations across grid cells belonging to each FI biome cluster. The main plant functional trade-offs are those returning on average the strongest correlations between a given pair of traits (as will be shown in Table 4). All analyses were performed under the R environment (http://www.r-project.org).

\section{RESULTS}

\section{Relationship between functional and species richness}

The global pattern of geographic variation of FR is an update of the map presented by Kleidon \& Mooney (2000), this time forcing climate data at $1^{\circ}$ resolution (Fig. 2). 


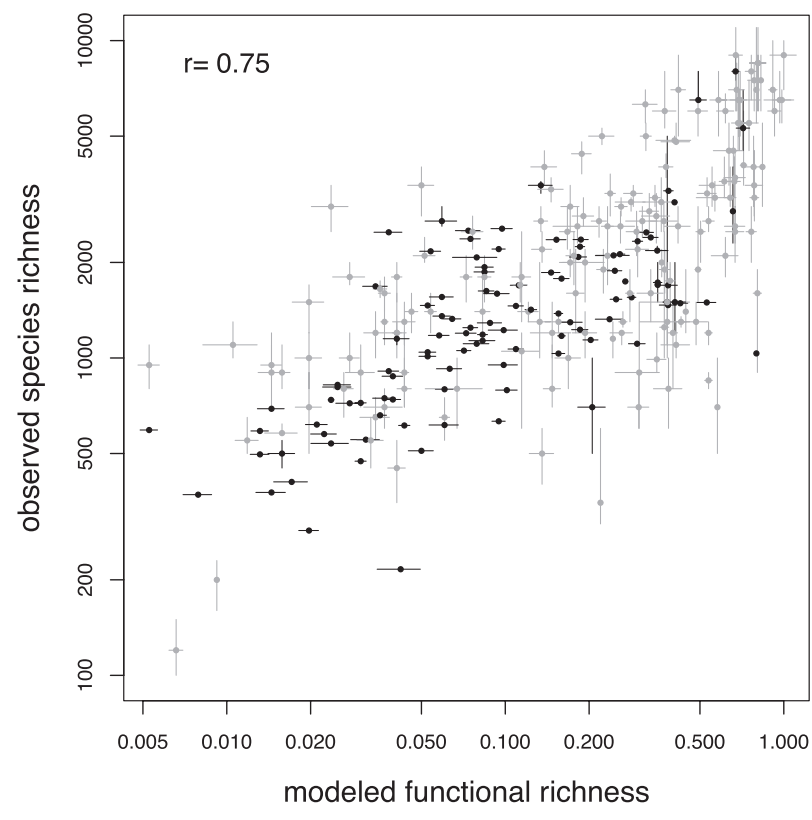

Figure 3 Correlation between modelled functional richness (FR) and observed species richness in vascular plants. Each point represents an ecoregion. Only reported species richness data of good (black points) and moderate (grey points) quality are considered. Error bars in the $x$-direction represent the potential uncertainty range as reported by Kier et al. (2005). Error bars in the $y$-direction represent the standard variation of modelled FR between grid cells within ecoregions. Since the uncertainty range in the $x$ - and $y$-directions increases, both $x$ - and $y$-axes are scaled logarithmically.

The correlation between modelled FR and observed vascular plant species richness (Kier et al., 2005) shows a strong Pearson's $r$ coefficient of 0.75 (Fig. 3 ). Furthermore, the figure emphasizes two interesting results: (1) the uncertainty range of the observed plant species richness in each ecoregion is positively associated with the modelled standard deviation of FR within an ecoregion (i.e. there is a significant positive correlation between the observed and modelled uncertainties, $r=0.51$, d.f. $=246, P<$ 0.001 , therefore the axes in Fig. 3 are displayed as a logarithmic scale); (2) the slope of the logarithmic relationship between modelled FR and observed plant species richness is less than one [major axis slope $( \pm 1 \mathrm{SD})=0.731 \pm 0.049, t=-5.46, P<0.001$; Legendre \& Legendre 1998], indicating that the relationship based on the raw values is not linear. However, this nonlinear relationship shows that plant species richness saturates with increasing FR, a result that is opposite to theoretical expectations and previous findings (FR saturates with increasing species richness; Diaz \& Cabido, 2001).

\section{Plant functional diversity in the trait space}

Our results show a monotonic relationship between the modelled plant FR and FD (Fig. 4). This suggests that with an increase in FR the realized trait space is progressively filled with new PGS. While FD increases exponentially at the lower range of
FR, it saturates rapidly at its higher range (Fig. 4). This saturation effect cannot be attributed to changes in the sample size (simulations not shown).

\section{Plant functional identity in the trait space}

According to the simple structure index, the optimal number of FI biome clusters is six. For the purpose of a direct comparison we aggregated the two other biome classifications into six categories: (1) tropical forest, (2) temperate forest, (3) boreal forest, (4) tundra, (5) savanna, (6) shrub and grasslands. We further aggregated hot and cold desert into a single category (7) for which JeDi does not simulate any vegetation cover (Fig. 5). The comparison with the dataset compiled by Ramankutty \& Foley (1999) shows a fair agreement for these major biome categories (kappa $=0.39$, Table 3 ). The comparison with the BIOME1 model is also in fair agreement (kappa $=0.43)$. When comparing the classification obtained from BIOME1 with the one by Ramankutty \& Foley (1999), a kappa of 0.47 indicates that empirical knowledge is only slightly better than the modelled FI in predicting the geographic pattern of biomes. Furthermore, more detailed kappa statistics suggest that predictions for forest categories are better than for other vegetation types (Table 3 ). These results support our hypothesis that the FI of regional plant assemblages can be scaled up to reproduce the global geographic patterns of biomes (Fig. 5).

The three strongest plant functional trade-offs (bivariate trait correlations) for each FI biome cluster are summarized in Table 4. Results indicate that a different hierarchy of functional trade-offs characterizes each biome. These trade-offs differ from the cost-benefit functions in Table 2 in that they emerge from the model architecture and are not explicitly implemented in the JeDi model. All correlations are negative in sign, supporting our definition of a plant functional trade-off (Table 1). In general, plant growth and survival under climatic constraints is primarily associated with allocation trade-offs. While allocation tradeoffs seem equally important to the functioning of all biomes, the best discriminatory traits of the FI clusters are plant growth responses to soil moisture ( $\mathrm{t} 01$ ), air temperature ( $\mathrm{t} 02$ ) and net productivity conditions (t09) (Table 5).

\section{DISCUSSION}

We have shown that biome and latitudinal diversity patterns emerge from first principles regarding plant functional tradeoffs and regional climatic constraints. Our analyses revealed three key results: (1) FR is a good surrogate for the observed plant species richness; (2) the modelled FR is best explained by FD in the model; (3) two main patterns of plant FI emerge at the global scale. The first is associated with regional plant assemblages with a relatively low mean FR (boreal forest $\mathrm{FR}=0.03$, tundra $\mathrm{FR}=0.01$, shrub- and grassland $\mathrm{FR}=0.02$ ) where a small increase in FR leads to a large increase in FD. The second is associated with regional plant assemblages with a relatively high 


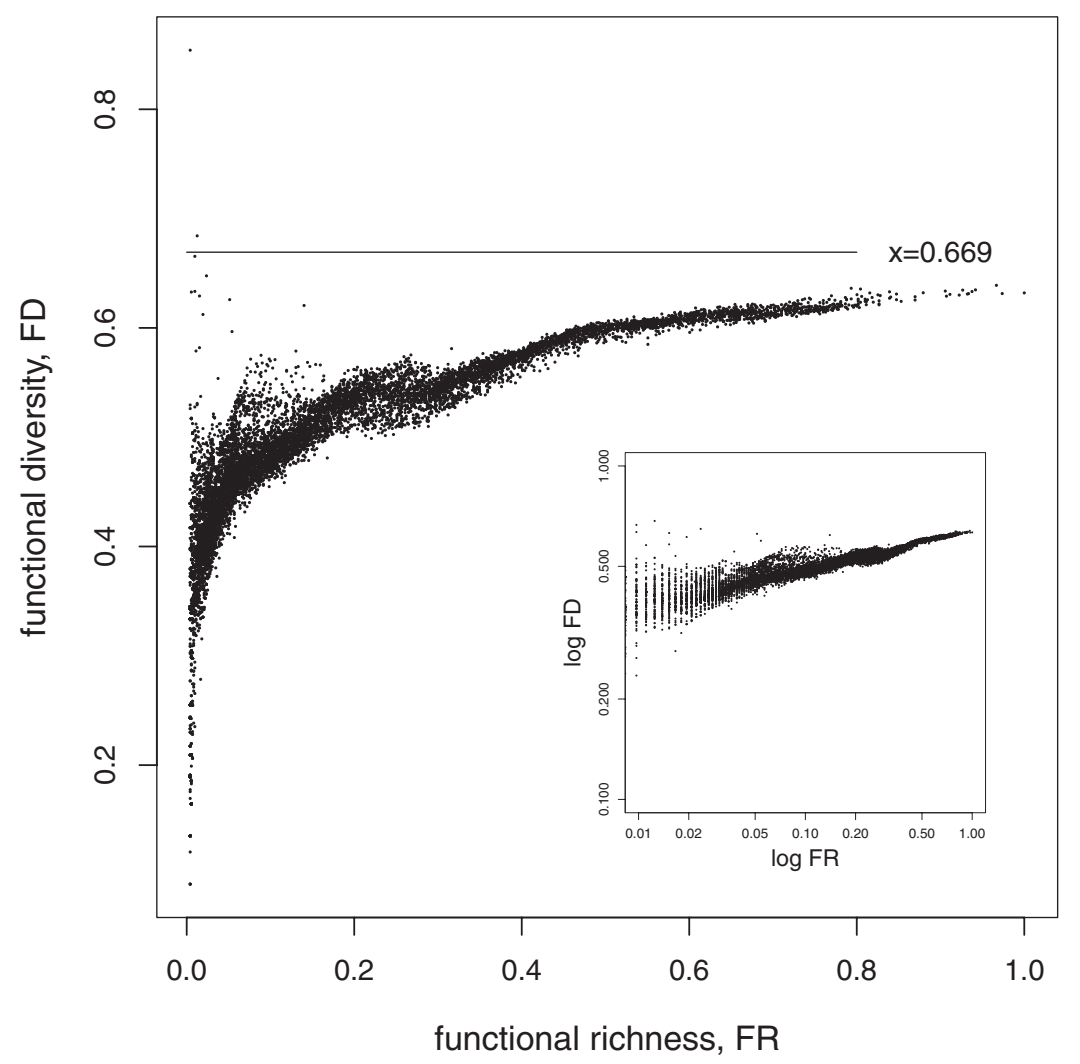

Figure 4 Relationship between functional richness (FR) and functional diversity (FD). The insert shows the same relationship on log-transformed axes. The line at $x=0.669$ represents the FD calculated from the global realized trait space, which combines all grid cells.

mean FR (savanna FR $=0.14$, temperate $\mathrm{FR}=0.10$, tropical forest $\mathrm{FR}=0.46$ ) where a large increase in FR leads to comparatively small increase in FD.

\section{Relationship between functional and species richness}

At large spatial scales many factors contribute to the observational errors in plant species richness. In contrast to the relatively species-poor temperate regions, tropical species-rich regions are remote and poorly investigated. Therefore, it may not come as a surprise that uncertainties in the range of observed plant richness increase with species richness (Kier et al., 2005). However, more surprising is that spatial uncertainties in the modelled plant FR within ecoregions similarly increase with plant FR. We see two possible explanations for this correlation between modelled and observed uncertainties: (1) ecoregions with more plant species tend to be larger in area, therefore they encompass more of the environmental heterogeneity (i.e. climatic, edaphic and ecosystem diversity); or (2) environmental heterogeneity is intrinsically higher in species-rich ecoregions, independent of their area. After verification, we can exclude the first possibility. There is no relationship between the size (in terms of area) of ecoregions and the number of plant species they host. The second possibility is partially supported by empirical climate-biodiversity relationships that evaluated the effect of environmental heterogeneity at different spatial grains and extents (Rahbek et al., 2007; Field et al., 2009). Rahbek et al. (2007) used ecosystem diversity variables for predicting the species richness of endemic birds of South America after accounting for spatial autocorrelation. Empirical relationships based on ecosystem diversity obtained explanatory power comparable to statistical models based on temperature and precipitation variables (Rahbek et al., 2007). Furthermore, at the spatial extent of an ecoregion it is also possible that climatic heterogeneity per se could translate into geographic variations in species richness (Field et al., 2009). Examples of this would include biodiversity hotspots such as the Andes and the Choco (Pacific coast, north-west Colombia), which exhibit high variability in the spatial and temporal distribution of climates. While this regional climatic variability may introduce considerable variation in species richness over small areas in the 'benevolent' tropics, at the 'harsh' high latitudes the same variability may cause species to go extinct.

We found a strong relationship between the modelled FR and the observed plant species richness at the level of ecoregions. However, the relationship based on raw (untransformed) values showed that FR saturates with increasing species richness, which is contrary to previous expectations (e.g. Diaz \& Cabido, 2001). In this context, and in absence of additional data on the global geographic distribution of plant species richness, we would argue that the relationship is quasi-linear primarily for the fol- 

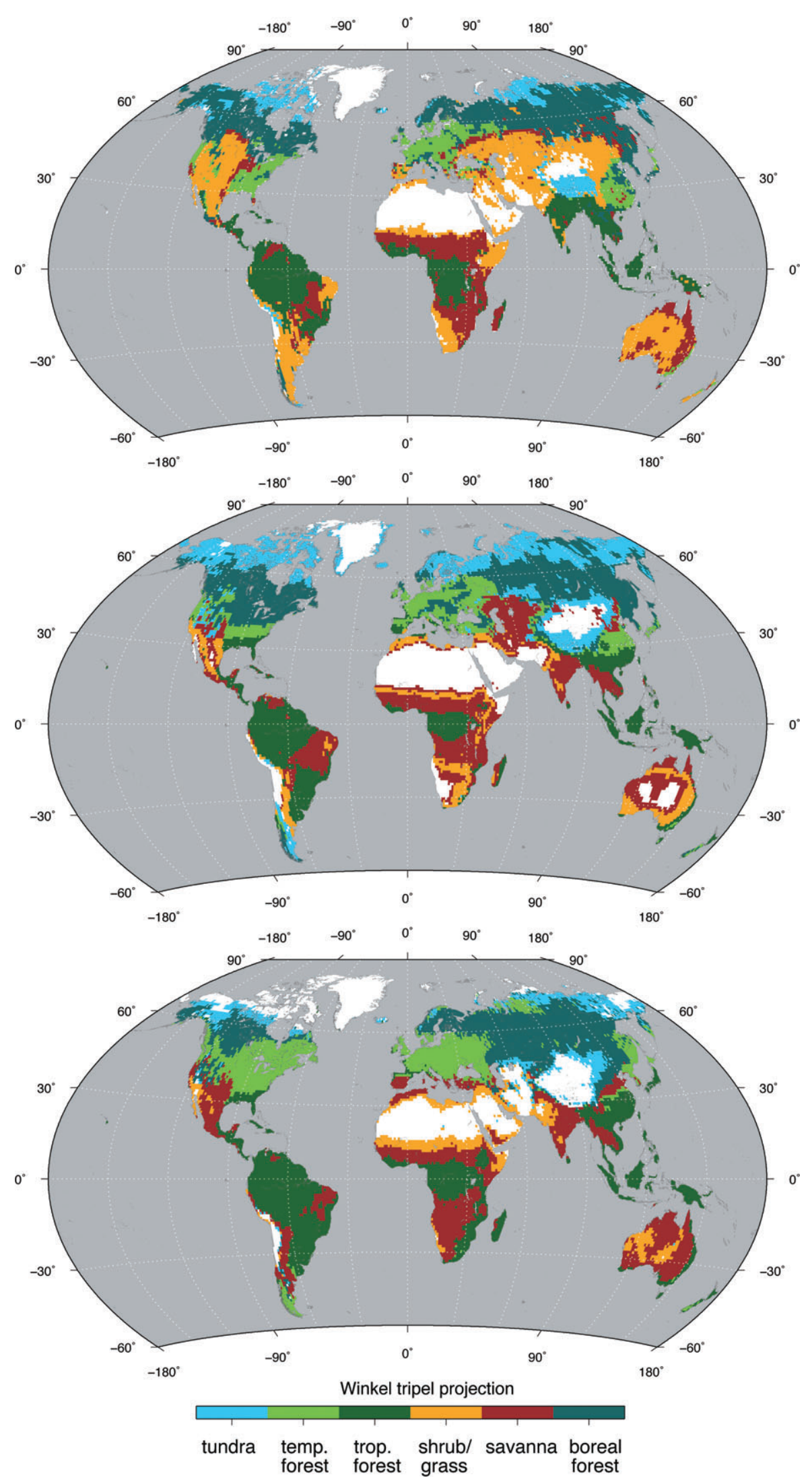

Figure 5 Biome patterns derived from satellite imagery (Ramankutty \& Foley, 1999; top), from the BIOME1 model (middle), and functional identity (FI) biome clusters (bottom). FI biome clusters are plotted in the same colour as their geographically corresponding vegetation categories. White areas are classified as cold and hot deserts. 
Table 3 Kappa statistics comparing the biome clusters based on functional identity (FI) with the vegetation classification schemes of Ramankutty \& Foley (1999) (RF1999) and the BIOME1 model.

\begin{tabular}{llll}
\hline Biome & $\begin{array}{l}\text { RF1999 vs. } \\
\text { FI cluster }\end{array}$ & $\begin{array}{l}\text { RF1999 vs. } \\
\text { BIOME1 }\end{array}$ & $\begin{array}{l}\text { FI cluster vs. } \\
\text { BIOME1 }\end{array}$ \\
\hline Tropical forest & 0.51 & 0.55 & 0.74 \\
Temperate forest & 0.35 & 0.43 & 0.36 \\
Boreal forest & 0.49 & 0.50 & 0.44 \\
Tundra & 0.21 & 0.52 & 0.27 \\
Savanna & 0.26 & 0.35 & 0.36 \\
Shrub-grassland & 0.16 & 0.38 & 0.56 \\
Deserts & 0.54 & 0.53 & 0.35 \\
Global & 0.39 & 0.47 & 0.43 \\
\hline
\end{tabular}

Kappa statistics are calculated for seven major global vegetation types. A kappa of 0 between two sets of categorical variables indicates no better agreement than expected by chance, while a kappa of 1 indicates perfect agreement. A kappa around 0.4 , around 0.6 or around 0.75 indicates a fair, good or very good agreement, respectively (after Monserud \& Leemans, 1992). lowing reason. As already pointed out, the uncertainty in the estimated number of plant species increases with the richness of an ecoregion. This could lead to an underestimation of plant species richness with increasing FR. Support for this explanation was provided by extracting the maximum of the plant species richness range reported by Kier et al. (2005) for each ecoregion and recalculating the slope of the relation between logtransformed values of the maximum species richness and FR. We found that the correlation remains unaffected (Pearson's $r=$ 0.73 ) and the slope gets closer to 1 [major axis slope $( \pm 1 \mathrm{SD})=$ $0.7931 \pm 0.051, t=-4.0, P<0.001]$.

Our model is based on the assumption of constant functional spacing among PGS, which arises from the Monte Carlo procedure we used to construct the potential trait space. In other words, the functional density of the trait space among regional plant assemblages remains constant, even along environmental gradients. Diaz \& Cabido (2001) suggest that this assumption, if valid, would indeed lead to a quasi-linear relationship between functional and species richness. However, because of biotic interactions this assumption is rather the exception than the norm in real world plant communities (Diaz \& Cabido, 2001).

Table 4 The three most dominant plant functional trade-offs associated with each functional identity (FI) biome cluster (see Table 2 for trait description).

\begin{tabular}{lllllrl}
\hline Biome & Trade-off & $r$ & Trade-off & $r$ & Trade-off & $r$ \\
\hline Tropical forest & t06 vs. t04 & $-0.45(0.02)$ & t06 vs. t03 & $-0.36(0.03)$ & t06 vs. t05 & $-0.35(0.02)$ \\
Temperate forest & t06 vs. t05 & $-0.47(0.10)$ & t06 vs. t04 & $-0.46(0.10)$ & t04 vs. t03 & $-0.32(0.09)$ \\
Boreal forest & t06 vs. t05 & $-0.51(0.07)$ & t06 vs. t04 & $-0.46(0.14)$ & t04 vs. t03 & $-0.42(0.09)$ \\
Tundra & t06 vs. t05 & $-0.73(0.14)$ & t07 vs. t03 & $-0.69(0.17)$ & t09 vs. t06 & $-0.63(0.40)$ \\
Savanna & t06 vs. t04 & $-0.51(0.03)$ & t06 vs. t03 & $-0.39(0.06)$ & t06 vs. t05 & $-0.30(0.08)$ \\
Shrub-grassland & t06 vs. t04 & $-0.57(0.22)$ & t10 vs. t03 & $-0.50(0.31)$ & t06 vs. t03 & $-0.45(0.21)$ \\
\hline
\end{tabular}

Plant functional trade-offs were defined as the negative correlation between two plant functional traits $(\mathrm{t})$ among all plant growth strategies at a spatial resolution of $1^{\circ}$. Pearson's $r$ correlation coefficient $( \pm 1 \mathrm{SD})$ gives the relative importance of a functional trade-off.

Table 5 Mean plant traits ( \pm 1 SD) among grid cells of each FI biome cluster.

\begin{tabular}{lcccccc}
\hline Functional trait & Tropical forest (SD) & Temperate forest (SD) & Boreal forest (SD) & Tundra (SD) & Savanna (SD) & Shrub-grassland (SD) \\
\hline t01 & $9.7(0.75)$ & $8.5(1.9)$ & $6.3(1.2)$ & $6.4(3.6)$ & $9.3(1.0)$ & $11.6(6.0)$ \\
t02 & $10.3(1.0)$ & $10.5(1.8)$ & $6.7(1.4)$ & $6.7(3.2)$ & $9.6(0.9)$ & $6.1(3.6)$ \\
t03 & $0.24(0.003)$ & $0.24(0.013)$ & $0.21(0.014)$ & $0.24(0.027)$ & $0.24(0.006)$ & $0.26(0.032)$ \\
t04 & $0.28(0.008)$ & $0.30(0.014)$ & $0.33(0.014)$ & $0.33(0.021)$ & $0.28(0.009)$ & $0.26(0.025)$ \\
t05 & $0.34(0.006)$ & $0.34(0.015)$ & $0.35(0.013)$ & $0.36(0.034)$ & $0.34(0.007)$ & $0.37(0.041)$ \\
t06 & $0.35(0.004)$ & $0.34(0.013)$ & $0.35(0.016)$ & $0.34(0.035)$ & $0.35(0.009)$ & $0.34(0.035)$ \\
t07 & $0.35(0.031)$ & $0.28(0.021)$ & $0.25(0.024)$ & $0.17(0.042)$ & $0.28(0.023)$ & $0.15(0.039)$ \\
t08 & $0.37(0.019)$ & $0.36(0.027)$ & $0.32(0.029)$ & $0.32(0.073)$ & $0.35(0.018)$ & $0.39(0.074)$ \\
t09 & $10.09(1.15)$ & $1.0(1.63)$ & $0.07(0.17)$ & $0.03(0.13)$ & $6.62(2.95)$ & $3.52(1.76)$ \\
t10 & $0.49(0.008)$ & $0.48(0.023)$ & $0.47(0.029)$ & $0.35(0.047)$ & $0.48(0.015)$ & $0.40(0.07)$ \\
t11 & $5.93(0.569)$ & $6.26(0.397)$ & $7.02(0.245)$ & $7.35(0.399)$ & $7.33(0.405)$ & $8.50(0.392)$ \\
t12 & $0.55(0.017)$ & $0.58(0.03)$ & $0.57(0.023)$ & $0.57(0.081)$ & $0.64(0.038)$ & $0.72(0.061)$ \\
\hline
\end{tabular}

The units of $\mathrm{t} 03-\mathrm{t} 09, \mathrm{t} 10$ and $\mathrm{t} 12$ are fractions, $\mathrm{t} 01, \mathrm{t} 02$ and $\mathrm{t} 09$ are days and $\mathrm{t} 11$ is expressed in $\mathrm{g}$ of carbon. See Table 2 for details of trait descriptions. 
Biotic interactions, such as competition and facilitation, may cause a 'clustered' occupation of the trait space due to a convergence of species into functional groups. This effect would result in a relationship where FR saturates with increasing species richness and not the opposite. The constant functional spacing among PGS remains an assumption of the model and calls for further empirical tests on the relationship between plant species richness and FR along environmental gradients.

Nevertheless, empirical confirmation of a quasi-linear relation between FR and species richness may have profound implications for global change modelling. Global vegetation models usually represent species-rich ecosystems, with one or two PFTs, i.e. assuming species to be functionally more similar in the tropics than in temperate regions. These models therefore underestimate the ability of species-rich regions to biologically adapt under global change scenarios. A better representation of the PFTs in global vegetation models may thus alter some of the alarming results, such as the Amazon forest dieback, predicted by global warming scenarios (Betts et al., 2004). Under regional climate change, specific areas of the functional trait space may become accessible, thus allowing new species to invade. Simultaneously, other areas of the functional trait space may become inaccessible, triggering the displacement or extinction of resident species. In addition, novel regional climatic constraints may have no current analogue (Williams \& Jackson, 2007) and would constitute uncharted areas of the trait space for PFTs. The complex association between climate and regional plant assemblages suggests that PFTs should preferably emerge from the climatic constraints acting on plant functional trade-offs, rather than being prescribed based on empirical knowledge.

\section{Functional diversity in the trait space}

As a result of our simulations we found that plant FD increases with FR, indicating an expansion of the functional trait space. FD increases exponentially at the lower range of FR and then saturates rapidly at the higher range. An interpretation of this saturation effect indicates a structured trait space that expands unevenly with increasing FR. More precisely, we interpret this pattern as follows: (1) with increasing FR the realized trait space of regional plant assemblages expands preferentially along few main functional trade-off axes; (2) this trait space expansion is not even and leads to a rapid increase in functional heterogeneity; (3) at some point it becomes more constraining to expand in the direction of the main functional trade-offs, thus, new trait combinations (i.e. PGS) are selected that fall closer on average to the centroid of that regional plant assemblage; (4) this subsequent phase of trait space expansion (the third point above) leads to a saturation in FD. This interpretation is also partially supported by the fact that plant traits involved in the main functional trade-offs (i.e. allocation traits) are qualitatively different from the ones that discriminate the FI of biomes (i.e. temporal response traits associated with climatic tolerance). Alternatively, this saturation effect could also reflect the model implementation. In other words, it is not impossible that plant functional trade-offs in the model have different sensitivities to changes in climatic constraints. In their original paper, Kleidon \& Mooney (2000) conducted an extensive sensitivity analysis of the JeDi model. They concluded that although the geographic pattern of relative species richness is well preserved when model parameters are varied, the magnitude of the pattern can differ across regions.

\section{Functional identity in the trait space}

We found that clustering regional plant assemblages according to their convergence in FI allowed us to recover the Earth's major biomes. Trade-offs provide a process-oriented understanding of plant functional traits that can be implemented as cost-benefit functions. While the search for a functionally comprehensive functional classification has remained elusive in plant ecology (Lavorel et al., 2007), costs and benefits for plant growth and survival may provide a flexible modelling approach. Plant functional trade-offs could also help to bridge the gap between vegetation modellers focusing on coarse spatial scales and plant ecologists working primarily at the level of local plant communities. Because trade-offs are fundamental to plant growth and survival they can be studied independently of the spatial scale or level of organization. So far, global vegetation models based on PFTs have fallen short of recognizing that global patterns in vegetation physiognomy may emerge from the interplay between climatic constraints and plant functional trade-offs.

\section{Limitations of the model}

This version of JeDi makes use of allocation parameters that are not easily measurable in the field, therefore limiting an empirical evaluation of its mechanisms. In addition to the carbon pools considered by the model, plants must actively invest in nutrient acquisition (e.g. mycorrhiza) or build defences against pathogens, herbivores or fire. Other environmental or biological constraints such as fire frequency and grazing pressure are important processes in structuring the plant assembly of certain regions (e.g. savannas and grasslands). JeDi currently ignores competitive interactions among plant growth strategies and further assumes a constant spacing of the functional trait space. Although this last assumption is biologically wrong on purely conceptual grounds, it is possible that competitive interactions are only secondary to climatic constraints when it comes to modelling species FR and FI over large spatial scales. While processes of competition and dispersal are currently implemented in a new version of the JeDi model, it is still simplistic compared with the amount of physiological and morphological detail considered in 'better' vegetation models (e.g. wilting point, frost limitation, bark thickness and many other traits). However, rather than prescribing plant functional traits from empirical knowledge, this simplicity allowed us to consider the trade-offs between plant functional traits.

\section{Predictions to be tested in future experiments}

Considering the above limitations, it is noteworthy that the model is able to simulate observed global patterns of both plant 
species richness and vegetation physiognomy. Our simulations show the effect of climatic constraints and plant functional trade-offs on biodiversity and biome patterns. Therefore, the JeDi model can be used as a 'climate only' model against which other ecological and evolutionary hypotheses can be tested. As quoted from Pausas \& Austin (2001): 'It is essential to consider the abiotic environmental (e.g. climatic) control over the niche dimensions of individual species and patterns of local species richness before attempting to develop general principles for diversity theory'.

In conclusion, we list two readily testable predictions emerging from this study in the form of open questions. By doing so, we hope to stimulate collaborations between vegetation modellers and plant community ecologists.

1. Is the positive monotonic relationship between species richness and functional diversity steeper in the boreal forest, tundra and grassland ecosystems in comparison with species-rich ecosystems like the savannas and tropical forests?

2. Does the predictive accuracy of coupled atmospherebiosphere models increase when the response of vegetation to climatic constraints is made more dynamic and adaptive?

Evaluating these questions in the light of climatic constraints and plant functional trade-offs may advance our understanding of the processes shaping coarse-scale biogeographic patterns.

\section{ACKNOWLEDGEMENTS}

The authors gratefully acknowledge the technical support with the model code provided by Kerstin Sickel and Steffen Richter. The quality of the manuscript was substantially improved following suggestions by the editors David Currie and Bill Shipley, Ronald P. Neilson and two anonymous referees. Finally, B.R. would like to thank the Max Planck Society for supporting the independent research group 'Biospheric Theory and Modelling'.

\section{REFERENCES}

Ackerly, D.D., Dudley, S.A., Sultan, S.A., Schmitt, J.D., Coleman, J.S., Linder, C.R., Sandquist, D.R., Geber, M.A., Evans, A.S., Dawson, T.E. \& Lechowic, M.J. (2000) The evolution of plant ecophysiological traits: recent advances and future directions. BioScience, 50, 979-995.

Anderson, M.J. (2001) A new method for non-parametric multivariate analysis of variance. Austral Ecology, 26, 32-46.

Betts, R.A., Cox, P.M., Collins, M., Harris, P.P., Huntingford, C. \& Jones, C.D. (2004) The role of ecosystem-atmosphere interactions in simulated Amazonian precipitation decrease and forest dieback under global climate warming. Theoretical and Applied Climatology, 78, 157-175.

Box, E.O. (1981) Predicting physiognomic vegetation types with climate variables. Vegetatio, 45, 127-139.

Box, E.O. (1996) Plant functional types and climate at the global scale. Journal of Vegetation Science, 7, 309-320.

Currie, D.J., Mittelbach, G.G., Cornell, H.V., Field, R., Guégan, J.F., Hawkins, B.A., Kaufman, D.M., Kerr, J.T., Oberdorff, T., O’Brien, E.M. \& Turner, J.R.G. (2004) Predictions and tests of climate-based hypotheses of broad-scale variation in taxonomic richness. Ecology Letters, 7, 1121-1134.

Diaz, S. \& Cabido, M. (2001) Vive la difference: plant functional diversity matters to ecosystem processes. Trends in Ecology and Evolution, 16, 646-655.

Ehleringer, J.R. \& Monson, R.K. (1993) Evolutionary and ecological aspects of photosynthetic pathway variation. Annual Review of Ecology and Systematics, 24, 411-439.

Field, R., Hawkins, B.A., Cornell, H.V., Currie, D.J., Diniz-Filho, J.A.F., Guégan, J.-F., Kaufman, D.M., Kerr, J.T., Mittelbach, G.G., Oberdorff, T., O'Brien, E.M. \& Turner, J.R.G. (2009) Spatial species-richness gradients across scales: a metaanalysis. Journal of Biogeography, 36, 132-147.

Francis, A.P. \& Currie, D.J. (2003) A globally consistent richness-climate relationship for angiosperms. The American Naturalist, 161, 523-536.

Garnier, E., Cortez, J., Billes, G., Navas, M.L., Roumet, C., Debussche, M., Laurent, G., Blanchard, A., Aubry, D., Bellmann, A., Neill, C. \& Toussaint, J.P. (2004) Plant functional markers capture ecosystem properties during secondary succession. Ecology, 85, 2630-2637.

Grime, J.P. (1974) Vegetation classification by reference to strategies. Nature, 250, 26-31.

Hawkins, B.A., Field, R., Cornell, H.V., Currie, D.J., Guégan, J.-F., Kaufman, D.M., Kerr, J.T., Mittelbach, G.G., Oberdorff, T., O’Brien, E.M., Porter, E.E. \& Turner, J.R.G. (2003) Energy, water, and broad-scale geographic patterns of species richness. Ecology, 84, 3105-3117.

Hillebrand, H. (2004) On the generality of the latitudinal diversity gradient. The American Naturalist, 163, 192-211.

Holdridge, L.R. (1947) Determination of world plant formations from simple climatic data. Science, 105, 367-368.

von Humboldt, A. (1808) Ansichten der Natur. Cotta, Stuttgart und Tübingen.

Kier, G., Mutke, J., Dinerstein, E., Ricketts, T.H., Küper, W., Kreft, H. \& Barthlott, W. (2005) Global patterns of plant diversity and floristic knowledge. Journal of Biogeography, 32, 1107-1116.

Kleidon, A. \& Mooney, H.A. (2000) A global distribution of biodiversity inferred from climatic constraints: results from a process-based modelling study. Global Change Biology, 6, 507523.

Kleidon, A., Adams, J.M., Pavlick, R. \& Reu, B. (2009) Simulated geographic variations of plant species richness, evenness and abundance using climatic constraints on plant functional diversity. Environmental Research Letters, 4, 014007, doi: 10.1088/1748-9326/4/1/014007.

Köppen, W.P. (1936) Das geographische System der Klimate. Borntraeger, Berlin.

Kreft, H. \& Jetz, W. (2007) Global patterns and determinants of vascular plant diversity. Proceedings of the National Academy of Sciences USA, 104, 5925-5930.

Lavorel, S., Díaz, S., Cornelissen, J., Garnier, E., Harrison, S.P., McIntyre, S., Pausas, J.G., Pérez-Harguindeguy, N., Roumet, C. \& Urcelay, C. (2007) Plant functional types: are we getting any closer to the Holy Grail. Terrestrial ecosystems in a chang- 
ing world (ed. by J.G. Canadell, D. Pataki and L. Pitelka), pp. 149-164. Springer-Verlag, Berlin.

Legendre, P. \& Legendre, L. (1998) Numerical ecology. Elsevier, Amsterdam.

Mittelbach, G.G., Steiner, C.F., Scheiner, S.M., Gross, K.L., Reynolds, H.L., Waide, R.B., Willig, M.R., Dodson, S.I. \& Gough, L. (2001) What is the observed relationship between species richness and productivity? Ecology, 82, 2381-2396.

Mokany, K., Raison, R.J. \& Prokushkin, A. (2006) Critical analysis of root:shoot ratios in terrestrial biomes. Global Change Biology, 12, 84-96.

Monserud, R.A. \& Leemans, R. (1992) Comparing global vegetation maps with the kappa-statistics. Ecological Modelling, 62, 275-293.

Neilson, R.P. (1995) A model for predicting continental-scale vegetation distribution and water balance. Ecological Applications, 5, 362-385.

Olson, D.M., Dinerstein, E., Wikramanayake, E.D., Burgess, N.D., Powell, G.V.N., Underwood, E.C., D’Amico, J.A., Itoua, I., Strand, H.E., Morrison, J.C., Loucks, J., Allnutt, T.F., Ricketts, T.H., Kura, Y., Lamoreux, J.F., Wettengel, W.W., Hedao, P. \& Kassem, K.R. (2001) Terrestrial ecoregions of the world: a new map of life on earth. BioScience, 51, 933-938.

Pausas, J.G. \& Austin, M.P. (2001) Patterns of plant species richness in relation to different environments: an appraisal. Journal of Vegetation Science, 12, 153-166.

Petchey, O.L. \& Gaston, K.J. (2002) Functional diversity (FD), species richness and community composition. Ecology Letters, 5, 402-411.

Prentice, I.C., Cramer, W., Harrison, S., Leemans, R., Monserud, R.A. \& Solomon, A.M. (1992) A global biome model based on plant physiology and dominance, soil properties and climate. Journal of Biogeography, 19, 117-134.

Rahbek, C., Gotelli, N.J., Colwell, R.K., Entsminger, G.L., Rangel, T.F.L.V.B. \& Graves, G.R. (2007) Predicting continental-scale patterns of bird species richness with spatially explicit models. Proceedings of the Royal Society B: Biological Sciences, 274, 165-174.

Ramankutty, N. \& Foley, J.A. (1999) Estimating historical changes in global land cover: crop-lands from 1700 to 1992. Global Biogeochemical Cycles, 13, 997-1027.

Raunkiaer, C. (1934) The life forms of plants and statistical plant geography. Clarendon Press, Oxford.

Reich, P.B., Wright, I.J., Cavender-Bares, J., Craine, J.M., Oleksyn, J., Westoby, M. \& Walters, M.B. (2003) The evolution of plant functional variation: traits, spectra, and strategies. International Journal of Plant Sciences, 164, 143-164.

Reineking, B., Veste, M., Wissel, C. \& Huth, A. (2006) Environmental variability and allocation trade-offs maintain species diversity in a process-based model of succulent plant communities. Ecological Modelling, 199, 486-504.

Schimper, A.F.W. (1898) Pflanzengeographie auf physiologischer Grundlage. Fischer, Jena.

Schwinning, S. \& Ehleringer, J.R. (2001) Water use trade-offs and optimal adaptations to pulse-driven arid ecosystems. Journal of Ecology, 89, 464-480.
Sheffield, J., Goteti, G. \& Wood, E.F. (2006) Development of a 50 -year high-resolution global dataset of meteorological forcings for land surface modeling. Journal of Climate, 19, 3088 3111.

Thornley, J.H.M. (1972) Balanced quantitative model for rootshoot ratios in vegetative plants. Annals of Botany, 36, 431441.

Tilman, D. (1988) Plant strategies and the dynamics and structure of plant communities. Princeton University Press, Princeton, NJ.

Tilman, D. (1990) Constraints and tradeoffs: toward a predictive theory of competition and succession. Oikos, 58, 315.

Violle, C., Navas, M.-L., Vile, D., Kazakou, E., Fortunel, C., Hummel, I. \& Garnier, E. (2007) Let the concept of trait be functional! Oikos, 116, 882-892.

Westoby, M., Falster, D.S., Moles, A.T., Vesk, P.A. \& Wright, I.J. (2002) Plant ecological strategies: some leading dimensions of variation between species. Annual Review of Ecology and Systematics, 33, 125-159.

Whittaker, R.H. (1975) Communities and ecosystems. Macmillan, New York.

Williams, J.W. \& Jackson, S.T. (2007) Novel climates, no-analog communities, and ecological surprises. Frontiers in Ecology and the Environment, 5, 475-482.

Woodward, F.I. (1987) Climate and plant distribution. Cambridge University Press, Cambridge.

Woodward, F.I. \& Kelly, C.K. (1997) Plant functional types: towards a definition by environmental constraints. Plant functional types: their relevance to ecosystem properties and global change (ed. by T.M. Smith, H.H. Shugart and F.I. Woodward), pp. 47-65. Cambridge University Press, Cambridge.

\section{BIOSKETCH}

Bjoern Reu is a PhD candidate in the Biospheric Theory and Modelling Group at the Max Planck Institute for Biogeochemistry in Jena, Germany. His research, under A.K. (together with J.D., K.B. and R. Pavlick), focuses on the processes shaping biogeographic patterns within the group's focus to understand the functional and adaptive role of biodiversity within the Earth system. The idea for this paper originated at the University of Bonn under the advice of S.S. and was further developed in joint seminars between the Biospheric Theory and Modelling Group and Organismic Biogeochemistry Group (R. Proulx) at the Max Planck Institute for Biogeochemistry. B.R. completed the model runs, data analysis and led the writing together with R. Proulx.

Editor: Bill Shipley 